\title{
Early Off Pump Coronary Artery Bypass Grafting After Carotid Artery Stenting is Safer than On Pump Coronary Artery Bypass Grafting in Male Patients
}

\author{
Tamer Owais ${ }^{\star 1,2}$, Mohammad El-Garhy ${ }^{1,3}$, Ashraf Fawzy ${ }^{2,4}$, Alaa Eldin Farouk ${ }^{2}$, Mahmoud Eldin ${ }^{5}$, Farouk Elalfy ${ }^{6}$, Martin Breuer ${ }^{1}$ and Thomas Kuntze ${ }^{1}$ \\ ${ }^{1}$ Heart Center (Cardiac Surgery and Cardiology), Central Clinic of Bad Berka, Germany \\ ${ }^{2}$ Department of Cardiothoracic Surgery, Cairo University Hospitals, Cairo, Egypt \\ ${ }^{3}$ Department of Cardiology, Menia University, Egypt \\ ${ }^{4}$ Department of Cardiothoracic Surgery, Saudi German Hospital, Madinah Munawarah, Saudi Arabia \\ ${ }^{5}$ Department of Vascular Surgery, Saudi German Hospital, Jeddah, Saudi Arabia \\ ${ }^{6}$ Department of Vascular Surgery, Saudi German Hospital, Madinah Munawarah, Saudi Arabia
}

*Corresponding author: Tamer Owais, Heart Centre (Cardiac Surgery and Cardiology), Zentralklinik Bad Berka, Robert-Koch Allee 9 , 99437 Bad Berka, Germany, Tel: 00491622397476; E-mail: tamerowaiss1976@yahoo.com

Received: March 06, 2018; Accepted: March 20, 2018; Published: March 22, 2018

Copyright: @ 2018 Owais T, et al. This is an open-access article distributed under the terms of the creative commons attribution license, which permits unrestricted use, distribution, and reproduction in any medium, provided the original author and source are credited.

\begin{abstract}
Objectives: Our aim was to evaluate and compare the safety and reliability of the early coronary bypass operation either with off-pump or on-pump technique after carotid artery stenting (CAS) in ischemic patients.

Patients and methods: The data of 312 patients with combined coronary and carotid artery disease treated with CAS between 2010 and 2017 prior to CABG in two different centers: Saudi German Hospital in Saudi Arabia and central clinic Bad Berka in Germany were retrospectively reviewed. 189 patients were operated off-pump; they were referred to as group A. The remaining 123 patients were operated on-pump (group B). All patients were submitted for CAS hours before the CABG. In both groups the double antiplatelet therapy was given before and after the carotid stenting and continued after the CABG. Patients in both groups were investigated pre-and postoperative by CT brain and CT angiography of carotid artery. Patients were followed up for stroke, bleeding, MI and mortality for 2 years.
\end{abstract}

Results: Patients of group A had less mortality, less post-operative bleeding, less myocardial infraction and less stroke after CABG than those in group $B$. The early timing for the CAS prior to CABG was more safe and reliable in group A.

Conclusion: Early Off-pump CABG after CAS is safer for patients; with fewer complications and less mortality than in On-pump CABG.

Keywords: Off pump; CABG; Carotid stenting

Abbreviations: AF: Atrial fibrillation; CABG: Coronary Artery Bypass Grafting; CAS: Carotid Artery Stenting; CCU: Coronary Care Unit; CEA: Carotid End Artrectomy; CPB: Cardio Pulmonary Bypass; EF: Ejection Fraction; IU: International Unit; MI: Myocardial Infarction; SD: Standard Deviation; TIA: Transient Ischemic Attack.

\section{Introduction}

The first technique using suture in the anastomosis was by Kolesov in 1964. This was the date of the real start of coronary revascularization that we know nowadays. Kolesov did not only launch the era of true CABG, but also, he is the godfather of the off-pump technique performing $82 \%$ of his cases for coronary revascularization without the $\mathrm{CPB}$ as he stated early the global inflammatory response of the CPB. 6 years later in 1970 he proved the reliability of the off-pump CABG by angiography follow up of his cases. Kolesov was not only the father of the surgical procedure but also the one who first introduced the magnifying goggles during surgery as well as the first surgeon ever to use clinically the coronary stapling technique in the anastomosis. Ever since the era of the heart lung machine flourished and all forgot the off-pump CABG [1].

The cardiac surgeries per se carry a risk of strokes. Statistically in the united states, the reported incidence of stroke in all cardiac surgeries is $2 \%$ in all cases operated, $6 \%$ in CABG patients and these figures increased to $12 \%$ in associated severe carotid artery lesions with cardiac surgeries $[2,3]$. In most of the cases this event is an intra and post-operative rather than preoperative insult. The proposed reasons were the atherosclerotic aorta, emboli from the machine (complement reaction), atrial fibrillation, mural or left atrial thrombi, cardiac tumours (myxoma), myocardial infarction and carotid lesions. The incidence of strokes with open heart increases with older ages $>70$ years, females, hypertension, diabetes, renal failure, COPD, low $\mathrm{EF}<40 \%$, aortic calcifications, carotid lesions, on-pump surgeries and long bypass time $[4,5]$.

Most reports concluded that- the incidence of strokes in off-pump CABG is decreased significantly compared to on-pump CABG. The 
Citation: Owais T, El-Garhy M, Fawzy A, Farouk AE, Eldin M, et al (2018) Early Off Pump Coronary Artery Bypass Grafting After Carotid Artery Stenting is Safer than On Pump Coronary Artery Bypass Grafting in Male Patients. J Cardiovasc Dis Diagn 6: 312 . doi: $10.4172 / 2329-9517.1000312$

Page 2 of 6

incidence was decreased between 50-58\% in Off-pump than On-pump, with decreased in-hospital mortality due to stroke too [6-8].

An interesting study in 2004 reported a lower incidence of strokes with the off-pump (1\%) and $2.5 \%$ in on-pump. $90 \%$ of strokes in offpump had no neurologic deficits and they were delayed strokes (average 4 days after surgery) while they were early after the on-pump (average after 2 days). Notably the mortality rate was higher with early strokes [9].

The above-mentioned causes of strokes are mostly applied for the on-pump surgeries while the reasons of strokes with the off-pump are mostly attributed to the arrhythmias, carotid diseases and the atherosclerotic intracranial vessels. The protocols of most studies of the off-pump recommended not discontinuing the antiplatelets before surgery especially in high risk patients [10-12].

With the belief of some authors that the Off-pump surgery is more reliable regarding the incidence of stroke, there is still a controversy and contradicting strategies to treat the associated carotid artery disease. The technique of solving the problem and the timing with the CABG or cardiac surgeries are still debatable. CABG after carotid procedures carry the risk of MI and the necessity to take double antiplatelet therapy which may lead to postoperative bleeding or coagulopathies. CABG before solving the problem of the carotids carries the risk of post CABG strokes. Simultaneous CABG and carotid end artrectomy (CEA) or CAS may lead to devastating results and even the strategy within this plan is variable as some authors may start the carotid procedure under general anesthesia after harvesting the grafts for CABG and some others preferred to do the carotid procedures under local anesthesia then they start the CABG just after the carotid was accomplished. Whether doing before, after or simultaneous; there was still the risk of the cardiopulmonary bypass (CPB) [13-15].

Moreover; the choice between the two strategies for carotid stenosis treatment has been long debated. For 20 years, the value of the CEA overweighed the aspirin. Since the FDA approval for the carotid stents in August 31, 2004 [15] there is a continuous debate for the indications of both the CAS and the CEA. The American College of Cardiology (ACC) and multisociety updated the guidelines in 2016 for the indications of either of them (Table 1) [16,17].

\section{Patients and Methods}

Our retrospective observational study took place between 01/2010 and 01/2017 where 312 patients were operated for combined CABG and carotid stent. The patients were operated in two different centres; Saudi German Hospital in Saudi Arabia and central clinic of Bad Berka in Germany using the same strategy in timings for both the CABG and the carotid stenting (first the CAS then the CABG hours after the stent). 189 patients were operated off-pump and they were referred as group A. Group B patients were operated on-pump (123 patients).

All patients of both groups were submitted to the CAS under local anesthesia. The same pre- and post-operative investigations were performed for both groups with follow up period of 2 years for all patients regarding the incidence of strokes, TIAs, MI and mortality.

\section{Inclusion criteria}

All male patients whom were operated for combined early CABG after carotid stent between 01/2010 and 01/2017.

\section{Exclusion criteria}

1. Recent or old strokes

2. Left ventricular ejection fraction less than $40 \%$.

3. Associated intracranial artery diseases

4. Patients on hemodialysis.

5. Associated atrial fibrillation, ventricular aneurysm, mural thrombus, recent MI (3 weeks or less) and redo cardiac operations.

6. If the Intra-Aortic Balloon (IAB) was inserted.

\section{Pre-operative investigations}

All patients were submitted for $\mathrm{CBC}$, Liver and kidney functions, Coagulation profile, Thyroid profile, CT brain and CT angio for the great vessels showing the intracranial parts. Transthoracic echocardiography, thorough neurological assessment clinically, femoral duplex, Off-pump CABG technique.

The used procedure in all cases of group A was off-pump without $\mathrm{CPB}$. The procedure was performed early after the carotid procedure from 1 hour to 22 hours maximum. All patients received double antiplatelet therapy. The used approach median full sternotomy. The hemodynamics of all patients were stable, the systolic blood pressure was almost always kept above $110 \mathrm{mmHg}$. All patients had full revascularization. Protamine was given as required according to the surgeon's decision. It was not needed in 37 patients only.

Carotid artery stent (CAS) technique was performed for all patients in group A and B. The patients were in the supine position under local anesthesia in the Cath Lab Room. Heparin $80 \mathrm{IU} / \mathrm{Kg}$ was given IV. Seldinger technique was used to insert a hydrophilic guide-wire; the puncture was dilated reaching to $6 \mathrm{~F}$ sheath. The guide-wire was advanced under fluoroscopy. The catheter was advanced and directed to the selected CCA (right or left). The guide wire was advanced to the ECA guiding an $\mathrm{H} 1$ catheter in the ECA. An angiography of the carotids was done. Balloon angioplasty was done prior to the deployment of the stent. A final look angiogram was performed before withdrawal of the wires.

\section{Follow up investigations}

1. Thorough neurological examination.

2. Blood picture, Liver and kidney functions, and Coagulation profile.

3. Carotid duplex performed just few hours after the CABG.

4. Transthoracic echocardiography.

5. CT brain and CT angiography for the carotids, CT angio for the carotids was performed before patient's discharge from hospital, 6 months and 2 years after the operations.

\section{Statistical analysis}

Standard definitions were used for patient variables and outcomes. Categorical variables are expressed as percentages and continuous variables are expressed as mean \pm SD with range throughout the manuscript. All statistical analyses were performed with the IBM SPSS 19.0 software (IBM Corp, New York, USA). All p values of $<0.05$ were considered statistically significant. 
Citation: Owais T, El-Garhy M, Fawzy A, Farouk AE, Eldin M, et al (2018) Early Off Pump Coronary Artery Bypass Grafting After Carotid Artery Stenting is Safer than On Pump Coronary Artery Bypass Grafting in Male Patients. J Cardiovasc Dis Diagn 6: 312 . doi: $10.4172 / 2329-9517.1000312$

Page 3 of 6

\section{Results}

We reviewed the data of 312 patients grouped as A (Off-pump) and $B$ (on-pump). All patients of both groups were males. The mean age in group A was 52.16 years \pm 11.7 years and 51.3 years \pm 12.4 years in $\mathrm{B}$ with no statistical significant difference. There was also no statistical significant difference regarding other risk factors as smoking, hypertension, diabetes and lipid profile (Table 2).

\section{Multidisciplinary carotid artery stenting guidelines}

Indications

Symptomatic high surgical risk

\begin{tabular}{|c|c|}
\hline$>70 \%$ stenosis & American Heart Association (AHA) \\
\hline Difficult to access surgically & \multirow[t]{4}{*}{ American Stroke Association (ASA) } \\
\hline Associated medical conditions which increase surgical risk & \\
\hline Radiation induced stenosis & \\
\hline Restenosis after CEA & \\
\hline Unfavourable neck anatomy & Multisociety guidelines \\
\hline \multicolumn{2}{|l|}{ Symptomatic with average surgical risk } \\
\hline $\begin{array}{l}\text { Non-invasive imaging shows reduced internal carotid artery diameter to }>70 \% \text {. With risk } \\
<6 \% \text {. }\end{array}$ & Multisociety guidelines \\
\hline \multicolumn{2}{|l|}{$\begin{array}{l}\text { Invasive (angiography) imaging showing reduced diameter }>50 \% \text { with anticipated } \\
\text { perioperative stroke or mortality of }<6 \% \text {. }\end{array}$} \\
\hline Symptomatic with low or average risk & American Heart Association (AHA) \\
\hline Non-invasive imaging: $>70 \%$. & American Stroke Association (ASA) \\
\hline \multicolumn{2}{|l|}{ Invasive imaging: $>50 \%$. } \\
\hline \multicolumn{2}{|l|}{ Asymptomatic high surgical risk } \\
\hline Comorbid conditions & \multirow[t]{3}{*}{ Multisociety guidelines } \\
\hline Life expectancy & \\
\hline Other individual factors & \\
\hline Asymptomatic with unfavourable neck anatomy for arterial surgery. & Multisociety guidelines \\
\hline \multicolumn{2}{|l|}{ Asymptomatic average surgical risk } \\
\hline $\begin{array}{l}\text { Prophylactic CAS. To be evaluated as it is used in } 60 \% \text { stenotic lesions (by angio) or } 70 \% \\
\text { by validated Doppler ultrasound. }\end{array}$ & Multisociety guidelines \\
\hline
\end{tabular}

Table 1: The American Heart Association Multidisciplinary guidelines (2016) for carotid stenting [16].

The number of symptomatic patients for TIA were almost the same in both groups. The critical left main lesions of coronaries were 23 patients in A (12.1\%) and 14 patients in B (11.3\%) with p-value of 0.5. The cardiac function in both groups was almost equal with a mean EF $\%$ of $52 \% \pm 11.7 \%$ in $\mathrm{A}$ and $53 \% \pm 12 \%$ in $\mathrm{B}$. The average time between the CAS procedure and the start of CABG was: 4.2 hours \pm 2.3 hours in $\mathrm{A}$ and 4 hours \pm 1.9 hours in $\mathrm{B}$. The dose of the heparin used during CABG was markedly low in group A than B. Protamine was not needed in only 37 patients in group A (19.6\%) while it was given to all patients of B. Group A patients had better results than those of B; regarding the post-operative blood loss, duration of mechanical ventilation, $\mathrm{AF}$, re-exploration for bleeding and $\mathrm{CCU}$ stay.
The incidence of strokes was higher in group B than in A. The perioperative mortality in group A was $0 \%$, while in group B there were 2 mortalities; one related to the stroke and the other was due to multi-organ failure after extensive postoperative MI (Table 3 ).

The CAS was patent in all patients of group A post CABG, but it was occluded totally in one patient in B. Postoperatively there were 3 patients that had neurologic deficit while it was just one case who suffered of transient lower limb paresis which recovered after 4 days. The one year follow up as well as the 2 years follow up of both groups revealed no differences in each group regarding the cardiac status, the CAS or the neurological status. 
Citation: Owais T, El-Garhy M, Fawzy A, Farouk AE, Eldin M, et al (2018) Early Off Pump Coronary Artery Bypass Grafting After Carotid Artery Stenting is Safer than On Pump Coronary Artery Bypass Grafting in Male Patients. J Cardiovasc Dis Diagn 6: 312 . doi: $10.4172 / 2329-9517.1000312$

Page 4 of 6

\begin{tabular}{|l|l|l|l|}
\hline Variables & Group A (off-pump) No.189 patients & Group B (on-pump) No.123 patients. \\
\hline Age. Mean IQR & $52.16(42-63$ years) & $51.3(39-64$ years) \\
\hline Hypertensive & 82 pt. $43.33 \%$ & 51 pt. $41.46 \%$ & 0.14 \\
\hline Diabetic & 91 pt. $48.14 \%$ & 61 pt. $49.59 \%$ & 0.63 \\
\hline Smoker & 60 pt. $31.74 \%$ & 41 pt. $33.33 \%$ \\
\hline Dyslipidemic & 81 pt. $42.85 \%$ & 53 pt. $43.08 \%$ & 0.73 \\
\hline Status post TIAs & 33 pt. $17.46 \%$ & 20 pt. $16.26 \%$ \\
\hline Asymptomatic & 156 pt. $82.54 \%$ & 103 pt.83.74\% \\
\hline Pre-operative EF\% & $52 \% \pm 11.7 \%$ & $53 \% \pm 12 \%$ \\
\hline IQR: Interquartile Range; TIA: Transient Ischemic Attack; EF: Ejection Fraction. & 0.51 & 0.6 \\
\hline
\end{tabular}

Table 2: Baseline characteristic difference between the two groups.

\begin{tabular}{|c|c|c|c|}
\hline Variables & Group A. (off-pump) No.189 patients & Group B. (on-pump) No.123 patients. & P-value \\
\hline Heparin & $150 \mathrm{IU} / \mathrm{kg}$ & $450 \mathrm{lU} / \mathrm{kg}$ & 0.001 \\
\hline Heparin antidote & $152(80.42 \%)$ & $123(100 \%)$ & 0.0012 \\
\hline Postoperative mech. Vent. time in hours mean \pm SD & $5.3 \pm 2$ & $8.1 \pm 3.6$ & 0.02 \\
\hline Postoperative blood drain in $\mathrm{ml}$ mean $\pm \mathrm{SD}$ & $450 \pm 220$ & $600 \pm 350$ & $<0.001$ \\
\hline Postoperative strokes & $0 \%$ & $2.43 \%$ & 0.04 \\
\hline Postoperative CAS occlusion & $0 \%$ & $1(0.813 \%)$ & 0.21 \\
\hline Postoperative MI & $1(0.529 \%)$ & $2(1.626 \%)$ & 0.09 \\
\hline Postoperative AF & $12(6.34 \%)$ & $27(21.9 \%)$ & $<0.001$ \\
\hline Re-exploration & $1(0.529 \%)$ & $3(2.43 \%)$ & 0.00271 \\
\hline Postoperative bleeding. more than $1000 \mathrm{cc}$ & $2(1.05 \%)$ & $9(7.31 \%)$ & $<0.001$ \\
\hline Postoperative CCU stay time in days mean \pm SD & $2.7 \pm 1.1$ & $3.6 \pm 2$ & 0.06 \\
\hline Hospital stay in days mean $\pm S D$ & $8.8 \pm 1.5$ & $12.3 \pm 4.6$ & 0.02 \\
\hline Postoperative mortality & $0 \%$ & $2(0.813 \%)$ & $<0.03$ \\
\hline Post-operative neurologic deficits & $1(0.529 \%)$ & $3(2.43 \%)$ & 0.05 \\
\hline Mortality related to stroke & $0 \%$ & $1(0.813 \%)$ & 0.2 \\
\hline
\end{tabular}

Table 3: Operative and end points difference between the two groups.

\section{Discussion}

Since the revival of the off-pump strategy for CABG in the early 1990s; there have been more interests for this technique especially in South East Asia namely in Japan and South Korea where they perform $60 \%$ of CABG procedures off-pump; addressing its benefits regarding the postoperative complications attributed to the $\mathrm{CPB}$ and one of them is the neurological and peripheral vascular complications [18-22].
The overall incidence of stroke with $\mathrm{CPB}$ was reported to be between 1- 6\% with more incidence being ischemic [23-26]. In our study we excluded patients with possible source of thrombus rather than the carotid artery lesions being a stratified risk factor alone [4]. Other patients that had high risk for perioperative strokes whether they were cardiac or neurological factors were also excluded so as to avoid biased results. Strokes occurred only in the group where the CPB was used with an incidence of $2.43 \%$ and were all ischemic strokes. In patients performed off-pump there was no reported neurological insults. Despite our optimistic results; some other authors reported the 
same outcomes in both on and off-pump surgeries [7] and others had results near to ours with an incidence of $1 \%$ stroke in their series and $50 \%$ reduced rate than the on-pump [8,9]. The lower incidence of post CABG strokes we reported $(2.43 \%)$ with the on-pump compared to other reports that had almost double this (4.6\%-6\%) and our $0 \%$ incidence with the off-pump CABG was compared to other authors reported $1 \%$ might be due to our strict exclusion criteria which might add in return to the limitation of our study [23]. Meanwhile other studies reported higher incidence of strokes (10\%) with the staged procedures using off-pump CABG and CAS and the combined procedures (both hybrid and staged) [24-26].

The timing of the CAS procedures in all cases in A and B was few hours before the $C A B G$ and they all received double antiplatelet therapy pre-CABG and post as well. In group B there was significant bleeding post $\mathrm{CABG}$ that necessitated re-exploration in 3 patients $(2.43 \%)$ and all had no surgical sources. Despite many authors reported almost equal results of off-pump and on-pump as regards the complications and even they condemned the off-pump for the longterm outcomes, yet they reported lower incidences of strokes and they contradicts for the bleeding and re-exploration postoperatively $[27,28]$. The timing for CAS in our patients was few hours on average just before CABG, we do not see differences with other authors in the timing except if they used the hybrid strategy as this would never assess the neurologic complications that might happen during the CAS unless they had performed it under local anaesthesia [24]. Barrera and his colleagues reported 2 hours between the CAS and the CABG as the ideal timing and they recorded neither stroke nor mortality or MI or late complications. The limited number in their study may led to these results. Other authors used different strategy, but they reported almost same results where CABG was performed 5-6 weeks after the CAS and the clopidogrel was discontinued one week prior to CABG.

The hypothesis of selecting male patients was that, most of the study cohort group was collected from Saudi hospitals rather than the German hospital. The demographic distribution of the population in Saudi Arabia is tilting more towards male gender because the data were collected from a private hospital where most of the admitted patients are males who are employed in Saudi Arabia. It's worth noting that most of the foreigners employed in Saudi Arabia are living as singles leaving their families in home land. Consequently, we selected only males in our study.

\section{Conclusion}

It is safe and reliable to perform synchronous CAS/CABG starting by CAS under local anesthesia then no matter after how many hours we can perform the CABG which was preferred to be off-pump than using the $\mathrm{CPB}$ as it gave better outcomes regarding the early mortality, bleeding and strokes.

\section{Notes}

Ashraf Fawzy, Mahmoud Salah Eldin and Farouk Hassan Elalfy: conceived of the presented idea. A.B. developed the theory and performed the computations. Tamer Owais, Ashraf Fawzy, Martin Breuer, Thomas Kuntze: cardiac surgeon carried out bypass operations. Mahmoud Salah Eldin and Farouk Hassan Elalfy: carried out carotid stenting. Mohammad El Garhy: cardiologist followed up the patients after the operations and verified the analytical methods. Tamer Owais: took the lead in writing the manuscript and is the corresponding author. Mohammad El Garhy: contributed to the final version of the manuscript. Thomas Kuntze: supervised the findings of this work.

All authors discussed the results and provided critical feedback and helped shape the research, analysis and manuscript.

\section{References}

1. White CJ (2016) Carotid stenting Vs Endarterectomy ACC. J Am Coll Cardiol 69: 2266-2275.

2. Buxton BF, Galvin SD (2013) The history of arterial revascularization: from Kolesov to Tector and beyond. Ann Cardiothorac Surg 2: 419-426.

3. Naylor AR, Brown MJ (2011) Stroke after cardiac surgery and its association with asymptomatic carotid disease: an updated systematic review and meta-analysis. Eur J Vasc Endovasc Surg 41: 607-624.

4. Cray da Costa MA, Gauer MF, Gomes RZ, Schafranski MD (2015) Risk factors for perioperative ischemic strokes in cardiac surgeries. Rev Bras Cir Cardiovasc 30: 365-372.

5. Santos A, Washington C, Rahbar R, Benckart D, Muluk S (2012) Results of staged carotid endarterectomy and coronary artery bypass graft in patients with severe carotid and coronary disease. Ann Vasc Surg 26: 102-106.

6. Mahmoudi M, Hill PC, Xue Z, Torguson R, Ali G, et al. (2011) Patients with severe asymptomatic carotid artery stenosis do not have a higher risk of stroke and mortality after coronary bypass surgery. Stroke 42 : 2801-2805.

7. Brizzio ME, Zapolanski A, Shaw RE, Sperling JS, Mindich BP (2010) Stroke-related mortality in coronary surgery is reduced by the off-pump approach. Ann Thorac Surg 89: 19-23.

8. Chu D, Bakaeen FG, Dao TK, LeMaire SA, Coselli JS, et al. (2009) Onpump versus off-pump coronary artery bypass grafting in a cohort of 63,000 patients. Ann Thorac Surg 87: 1820-1827.

9. Sedrakyan A, Wu AW, Parashar A, Bass EB, Treasure T (2006) Off-pump surgery is associated with reduced occurrence of stroke and other morbidity as compared with traditional coronary artery bypass grafting: a metaanalysis of systematically reviewed trials. Stroke 37: 2759-2769.

10. Cao L, Qin Li, Qi Bi, Qin-Jun Yu (2011) Risk factors for recurrent stroke after coronary artery bypass grafting. J Cardiothorac Surg 6: 157-162.

11. Biancari F, Mosorin M, Rasinaho E, Lahtinen J, Heikkinen J, et al. (2007) Post-operative stroke after Off-pump versus On-pump coronary artery bypass surgery. J Thorac Cardiovasc Surg 133: 169-173.

12. Toumpoulis IK, Anagnostopoulos CE, Chamogeorgakis TP, Angouras DC, Kariou MA, et al. (2008) Impact of early and delayed stroke on inhospital and long-term mortality after isolated coronary artery bypass grafting. Am J Cardiol 102: 411-417.

13. Filsoufi F, Rahmanian PB, Castillo JG, Bronster D, Adams DH (2008) Incidence, topography, predictors and long-term survival after stroke in patients undergoing coronary artery bypass grafting. Ann Thorac Surg 85: 862-870.

14. Guzman LA, Costa MA, Angiolillo DJ, Zenni M, Wludyka P, et al. (2008) A systematic review of outcomes in patients with staged carotid artery stenting and coronary artery bypass graft surgery. Stroke 39: 361-365.

15. Fareed KR, Rothwell PM, Mehta Z, Naylor AR (2009) Synchronous carotid endarterectomy and off-pump coronary bypass: an updated, systematic review of early outcomes. Eur J Vasc Endovasc Surg 37: 375378.

16. Naylor AR, Mehta Z, Rothwell PM (2009) A systematic review and metaanalysis of 30-day outcomes following staged carotid artery stenting and coronary bypass. Eur J Vasc Endovasc Surg 37: 379-387.

17. Venkatachalam S, Shishehbor MH (2011) Management of carotid disease in patients undergoing coronary artery bypass surgery: is it time to change our approach?. Curr Opin Cardiol 26: 480-487.

18. Parolari A, Alamanni F, Cannata A, Naliato M, Bonati L, et al. (2003) Offpump versus on-pump coronary artery bypass: Meta-analysis of currently available randomized trials. Ann Thorac Surg 76; 37-40. 
Citation: Owais T, El-Garhy M, Fawzy A, Farouk AE, Eldin M, et al (2018) Early Off Pump Coronary Artery Bypass Grafting After Carotid Artery Stenting is Safer than On Pump Coronary Artery Bypass Grafting in Male Patients. J Cardiovasc Dis Diagn 6: 312 . doi: $10.4172 / 2329-9517.1000312$

Page 6 of 6

19. Bucerius J, Gummert JF, Walther T, Borger MA, Doll N, et al. (2005) Impact of off-pump coronary bypass grafting on the prevalence of adverse perioperative outcome in women undergoing coronary artery bypass grafting surgery. Ann Thorac Surg 79: 807-812.

20. Chen JW, Lin C H, Hsu RB (2015) Mechanisms of early and delayed stroke after systematic off-pump coronary artery bypass. J Formosan Med Assoc 114: 988-994

21. Babikian VL, Wolf PA (2005) Retinal and cerebral microembolism during on-pump and off-pump coronary artery bypass graft surgery. Circulation 112: 3816-3817.

22. Kim JB, Yun SC, Lim J, Hwang S (2014) Long-term survival following coronary artery bypass grafting: Off-Pump versus on-pump strategies. J Am Coll Cardiol 63: 2280-2288.

23. Bucerius J, Gummert JF, Borger MA, Walther T, Doll N, et al. (2003) Stroke after cardiac surgery: a risk factor analysis of 16,184 consecutive adult patients. Ann Thorac Surg 75: 472-478.
24. Yang $\mathrm{T}$, Zhang L, Wang $\mathrm{X}$, Dong $\mathrm{H}$, Jiang $\mathrm{X}$, et al. (2016) Revascularization by carotid artery stenting and off-pump coronary artery bypass. ANZ J Surg 86: 602-607.

25. Roger VL, Go AS, Lloyd-Jones DM, Benjamin EJ, Berry JD, et al. (2012) American Heart Association Statistics Committee and Stroke Statistics Subcommittee Heart disease and stroke statistics--2012 update: a report from the American Heart Association. Circulation 125: e2-e220.

26. Pires SL, Gagliardi RJ, Gorzoni ML (2004) Study of the main risk factors frequencies for ischemic cerebrovascular disease in elderly patients. Arq Neuropsiquiatr 62: 844-851.

27. Cantero MA, Rui Almeida MS, Galhardo R (2012) Analysis of immediate results of on-pump versus off-pump coronary artery bypass grafting surgery. Rev Bras Cir Cardiovasc 27: 38-44.

28. Lamy A, Devereaux PJ, Prabhakaran D, Taggart D, Hu S, et al. (2016) Five-year outcomes after off-pump or on-pump coronary-artery bypass grafting. N Engl J Med 375: 2359-2368. 